\title{
Leveraging Technology towards HR Excellence
}

\author{
${ }^{*}$ Dileep Kumar. M⒈, Srota Pandya ${ }^{2}$ \\ ${ }^{1}$ OYA-GSB, University of Utara, Malaysia \\ ${ }^{2}$ Acharya Institute of Management and Sciences, Bangalore, India \\ *dileep@uum.edu.my
}

\begin{abstract}
The last decade has seen a significant increase in the number of organizations gathering, storing and analyzing human resources data using Human Resource Information Systems (HRIS) (Ball, 2001; Barron et al., 2004; Hussain et al., 2007; Ngai \& Wat, 2006). HR to benefit almost every realm of business operations is leveraging technology. Many technology applications support Human Resource functions like erecruitment, employee tracking system, performance management software, e earning mode etc are helping dramatically to improve HR's ability to carry out effective talent management and get better employer brand. Integration of technology and HR not only mean harmonious co-existing but would also mean the journey towards business excellence. This paper explores the understanding on positive impact of Human Resource Information System (HRIS) currently in use for people management with perception on Information Communication Technology (ICT) applications adopted by many industries. The study follows qualitative research as its plan of action in gathering information. The information gathered in crosschecked with industry to cross check the reliability.
\end{abstract}

Key Words: Technology, Information Technology, Human Resource Information System (HRIS), Information Technology (ICT), Business Excellence

\section{Introduction}

Since the dawn of the information era, organizations are increasingly incorporating Information Communication Technology [ICT] in their work processes through different tools and techniques. With the evolution of Human Resource Management [HRM] from largely a maintenance function to a source of sustainable competitive advantage, it has become a challenge for Human Resource (HR) to transform from HR to electronic HR (e-HR) (Breaugh, (1992). The concept of Electronic Human Resource Management known as e-HRM meaning the adoption of technology in delivering Human Resource [HR] practices due to the digital revolution in the world is such a tool that organizations can employ to manipulate the performance and behavior of the people on whom they rely on to achieve business success (Breaugh, (1992). The researchers have viewed HR roles as transitioning from operational, administrative, functionally oriented, and reactive toward more strategic, consultative, business oriented, and proactive, respectively (Ulrich, 1997). HR is supported by technology application to enhance their strategic role. It is reported by many researchers that the use of a HRIS would reduce HR costs by automating information and reducing the need for large numbers of HR employees; by helping employees to control their own personal information; and by allowing managers to access relevant information and data, conduct analysis, make decisions, and communicate with others without consulting an HR professional (Awazu \& Desouza, 2003; Ball, 2001). According to Workforce, many smaller companies already use service providers for payroll, and training departments are rapidly incorporating online classes as well as video technology (Temple, 2000).The human resource management department is one functional area that is increasingly utilizing information technology. By capitalizing the new technologies in optimizing the internal HR process and meeting the business demands, HR is now become a strategic - value based partner rather than traditional cost driven partner. It is hypothesized in this research that the historical view of technology in HR as islands of information where there were no integration and no information has changed with the support of technology. Integrating Human Resource service delivery models and operating HR systems through technology the Human Resource Personnel are adding value to the company by freeing up time and money for more strategic HR activities. The primary purpose of this study was to address this issue by investigating how human resources (HR) functions may be influenced by extensive use of Information Technology applications. 


\section{Research Questions}

- How the Industries across global and national scenario have identified technology application towards business excellence?

- How human resources (HR) functions may be influenced by extensive use of Information Technology applications?

- How HRM functions and technology is integrated in business operations and strategic decisions?

- How the use of technology in HR has increased and become vital aspect of 'people related decisions' and business excellence etc?

\section{Influence of Technology on Business and HR}

Mayasoman (2007) indicates that the word 'technology' has become synonymous with 'information technology' as hardly any other technological development of the past would have impacted all spectrum of business as information technology has impacted. Irrespective of the kind of business, the deployment of information technology in one form or the other is a foregone conclusion. To manage and deploy technology in an effective way, all business organizations would need knowledge workers. Managing of these knowledge workers is the responsibility of HR function. Hence, the integration of technology and HR is an absolute must. Integration of technology and HR would not only mean harmonious co-existing but would also mean one enhancing and complementing the other i.e., technology is used to enhance effectiveness of HR and HR functions helps in adopting and managing change which technology deployment brings in. Integrating technology and HR functions, Sing (2006) indicates that HR management, as a function is responsible for deliverables like business strategy execution, administrative efficiency, employee contribution and capacity for change. All these are accomplished through what HR people do i.e., staffing, development, compensation, benefits, communicate organization design, high performing teams and so on. In majority of these areas, technology is being deployed. The technologies are making the biggest impact in the HR market. Cedar Enterprise Solutions, Inc. (2004), reports consistent with data observations from prior year survey results, continues to illustrate clear linkages between the introduction and use of workforce technology solutions and the achievement of organizational business goals.

The survey generated 22 findings that indicate prevalence of workforce technology use, the results achieved and the strategies used by successful organizations to achieve desired outcomes. There were three key indicators that stood out in support of the survey findings: 1) self-service is a fact of life in organizations today; 2) the benefits from adopting these technologies are powerful; and 3) consistent with industry statistics confirming the growth of technology in use in the workplace and HR is growing its leverage of technology to administer, deliver and analyze service to the workforce. While integrating the role of technology and administrative operations Mayasoman (2007) indicates that, the technology and HR are enablers of business. Integration of the two would mean not only harmonious co-existence but also leveraging one for the other. Leveraging of technology for HR would mean digitizing the mundane HR activities and automating the back office and transactional activities related to recruitment, performance management, career planning, training etc. Thus, they can play complementary roles. "Cutting-edge IT solutions have played a major role and contributed in large measure in the area of HR management. Some of the areas that have been substantially benefited are process automation, resource utilization, quick handling of employee grievances and timely and objective performance management. Starting with attendance and engagement of employees at work place, it helps tracking billability status of resources engaged in the business." (Rekhi Singh (2001) Chairman and CEO, R Systems International)

Human Resource Information System (HRIS): Over the last decade there has been a considerable increase in the number of organizations gathering, storing and analyzing information regarding their human resources through the use of Human Resource Information Systems (HRIS) software or other types of software which include HRIS functionality (Ball, 2001; Barron, Chhabra, Hanscome, \& Henson, 2004; Hussain, Wallace, \& Cornelius, 2007; Ngai \& Wat, 2006). Tannenbaum (1990) defines an HRIS as a system that will acquire, store, manipulate, analyze, retrieve, and distribute information about an organization's human resources. According to Gara (2001) and Walker (1982), a Human Resource Information System (HRIS) will help organizations "keep an accurate, complete, updated database that can be retrieved when needed from reports..." Some authors have proposed that the use of a HRIS would reduce HR costs by automating information and reducing 
the need for large numbers of HR employees; by helping employees to control their own personal information; and by allowing managers to access relevant information and data, conduct analysis, make decisions, and communicate with others without consulting an HR professional (Awazu \& Desouza, 2003; Ball, 2001). Ideally, with an appropriate use of HRIS, less people should be needed to perform administrative tasks such as record keeping and more time would be made available for HR managers to assist by providing data on a strategic level. Many of these authors believe the future to be bright for HRIS as it creates new paths for human resources and for the organizations that effectively use HRIS. One study even goes as far as to suggest that there is evidence that HRIS can improve shareholder value (Brown, 2002). Overman (1992) study indicates that the potential advantages of HRIS are faster information processing, greater information accuracy, improved planning and program development, and enhanced employee communications.

Some researcher's, finding further point out that the use of a HRIS would reduce HR costs by automating information and reducing the number of HR employees; by helping employees to control their own personal information; and by allowing managers to access relevant information and data, conducts analyses, make decisions, and communicate with others without consulting an HR professional (Awazu \& Desouza, 2003; Ball, 2001). Gallagher (1997) argues that HRIS can influence effectiveness in four ways: Firstly, with emphasis on increased productivity from the workforce, recruitment, short term working, temporary, and less redundancies. Secondly, it deals with the increasing demands made by legislation, which related to HR practices and the increased need to produce statistics for government. The third factor was the rate of the development of computer technology. The final factor was the increased availability of HRIS at lower costs. The professional body argued that effective HRIS use leads to efficiency (CIPD, 1999). "HRIS applications that not only address the functional aspects of Human Resource Management rather it manage complex-operational workflow processes including strategic functions of coordination and support of global operations for long term business advantages. The use of HR Software created better and faster results than when done on paper. The use of this new technology made life easier for both employees as well as employer" (Rony Mani Zacharia, Consultant HR, NES Global).

Technology and E-recruitment: E-recruitment has been an issue of interest over the past ten years. Internet is considered as the latest tool in hiring. It is a real revolution spreading over the world of job hunting and hiring. The term online recruitment, e-recruitment, cyber recruiting, or internet recruiting, imply the formal sourcing of job information online. The first references to e-recruitment appear in articles of the mid-1980s (Gentner, (1984) \& Casper, (1985). Hoffman (2001) defined e-recruitment as the utilization of internet for candidate sourcing, selection, communication and management throughout the recruitment process. Schreyer \& McCarter (1998) e-recruitment refers to the recruitment process, including placing job advertisements, receiving resumes, and building human resource database with candidates and incumbents. In recent years internet has made an impact on the human resource field (Bussler \& Davis, 2002). Organizational recruitment efforts have increasingly relied on computer technology and one area that has evolved is recruiting via the Internet, otherwise known as e-recruitment (Mottl, 1998), Hogler et al. (1998) \& HR Portal (2003), give the idea that employers can electronically advertise jobs, scan and store resumes, conduct test, and contact qualified applicants by using the power of the Internet to match people to jobs. The main advantages for Internet supported recruiting are:

- Lower costs of recruiting (savings in invitations for application, postal-costs, data-processing costs...). Quicker process of recruitment: period from the point when the need for a new employee is sensed until the point when he starts doing his job is, according to the research, cut for twelve days.

- Possibility to attract better and more candidates - invitation for application published on a website can also be spotted by those, who are currently not seeking new employment actively

There is a need for companies to have a conceptually sound framework (person: job-fit) and a cost-effective, speedy and convenient system (online testing) at their disposal to meet their personnel selection needs in a highly competitive environment (Chapman, \& Webster, (2003). These days, one way of doing so is via online recruitment, a method of attracting job candidates via the internet (Cullen, 2001). As a practice, it is agreed that e-HRM leads to considerable changes and therefore should be taken as an important development in the HR field (Lepak, \& Snell, (1998), Lengnick-Hall \& Moritz, (2003), Gueutal, \& Stone, (2005). In times of fierce competition, being able to attract high-quality human resources is considered a true competitive advantage for organizations (Gatewood, Gowan, and Lautenschlager, (1993), Rynes, (1991) \& Turban, \& Greening, 
(1997). This attraction of potential employees and to get them to accept offers of employment has given recent recognition to the important role that recruitment plays in assuring organizational success (Barber, (1998), Grossman, (2000), Nakache, (1997), \& Pomeroy, (2000). In order to face the challenges of mass recruitment and selection process a growing proportion of employers are using the online medium to recruit personnel. The e-recruitment process provides lower costs to the organization; selection of qualified candidates, reduction in the time for recruitment, facilitates the recruitment of right type of people with the required skills and supports the organization in its long-term journey to curb the cost of development and retain talented employees for better business sustenance. (Abhilash Shashikumar, HR Manager, Qatar))

Technology and Communication: Relating the use of technology in communication Elderman (2004) indicates that under e-HR initiative, all the human resources functional policies have been made available on Intranet Infact; whenever a new policy is formulated, the same is communicated all through organizations line and hosted on intranet. The policies can be referred and retrieved to any point of time saving valuable time for the employee seeking to refer a policy and for HR department, which was earlier had hard time going through the archive to retrieve it and communicating that to that employee. Further, intranet provides connection to the Intranet of other departments, which facilitated information flow unbridled. An employee of one department requiring information from another department and division no longer physically has to go to the department or make phone calls. They can now collect that information from the Intranet of that department itself. Thomas and Datta (2007) indicates that besides passing on the job related message, e-mail is also used for other activities like sending birthday messages to each and every employee by one of the senior most executives. The process in totally automated and the ingenious program picks up the birthday of an employee from the database and auto generates birthday message, it also picks-up the e-mail id of the employee from record and push the mail to his inbox. The employee gets his birthday wish from the seniormost executive in the morning itself as early as he opens his mailbox, which results satisfaction and happiness. The message is highly customized - it is embedded in the letterhead, complete with signature. The entire message can be printed and retained (Application of technology in Indian Oil Corporation).

Elderman (2004) further states that when a new employee comes on board, for instance, the HRIS creates emails that need to be generated so that security knows about the new employee, switchboard is notified and the legal department is advised about if there are any compliance or registration issues. Antony and Datta (2007) further indicates that most important feature of Indian Oil's intranet site is 'Employee Suvidha' It is a HR self-service portal, which over the time has helped employees a lot in finding out most crucial information about themselves. It has saved time for the employees as they are not worried at all for not keeping a track of their service related records like leaves, recovery of different types of loans, tax calculations etc. The tax card of the employees as well as pay slip, IT card, PF statement, Loan statements (Housing/Car) are just one click way. It even has a link provided to 'Objected Bills' of the employees. This has also saved a lot of time for the HR personnel, which was earlier spent on answering queries from the employees. The Intranet site has successfully linked with the SAP network, which has made record retrieving real time. Given the spread of global organizations and diversity of their operations, technologies have given following important advantages to organizations

- Intra departmental cooperation: The Online tools provided platforms for HR to reach diverse sections of employees and allow workers in different locations

- Inexpensive - Decreasing broadband and bandwidth costs, combined with savings in printing and shipping costs, technology provided organization with significant savings for communications.

- Accessibility to more information: Online tools allowed the members in the organization to have access to specific information sent, as well as to related information that's communicated on an ongoing basis.

- Better employee interaction: The Online tools provided platforms for better interaction between employees and employers on several context and issues and sharing of information's.

- Quick communication: Online tools let the organizational members to have quick interaction with each other avoiding delay in accessing the medium for communication.

- Document trail - By storing and tracking communications, as well as by providing the ability to follow changes in information, new media channels are helping documentation of evolution of communications in organizations 
- Greater feedback - Electronic communications provided an easy and intuitive outlet for individuals to collaborate on business operations and strategy, allowing for immediate and personalized feedback directly to the communicator or user.

- More focus group discussions - Online tools provided a forum to organizational members to have focus group discussions in improving productivity and profit.

- Effective documentation - Online tools let organization to go with better documentation across the departments and offices to have better analysis and interpretation on the data generated.

Browser based self-service systems for employees are also removing the administration burden for HR by lacing policies and procedures online and keeping employees up to date about the latest company news (Antony and Datta, 2007). "The HR department is well supported by an indigenously designed HRMS, which is also integrated to the company's intranet 'Connect'. It is the backbone of HR operations, especially for all day-today activities." He furthest reports that faster access to data at all times enables quick decision-making and releases bandwidth of HR team which can better utilize the time in effective employee engagement initiatives and adding strategic value to business. With the implementation of HRMS, the entire engine of people management goes on a fast track."(Karthik, 2007), Vice-president and Head HR, India, 24/7)

Technology and Employee self-service: In one of the international HRD conference proceeding, Antony \& Datta, (2007), indicates that Employee Self-Service (ESS) HRIS applications have gained in popularity over the last several years. Employee self-service is giving employees access to details about their payroll and pension information from any web-based location along with the ability to change information. Self-service for job-related functions allows employees to see what jobs are on offer and can be extended to external applicants who can identify open positions and send in their curriculum vita online. In a nutshell, these applications are Internet-based products that allow employees to view and/or edit information related to their HRIS applications employee file. Employees may be able to update their emergency contact information and personal contact information, or even change their address when necessary. A number of the self-service applications also include Benefits Open Enrollment. Employees often like this arrangement because they're in charge of their own data, and Human Resources (HR) professionals like it because it cuts down on their input workload. The internal HR self-service portal (Employee Service), which is helping employees a lot in finding out most crucial information about themselves. It is saving time for the employees as they are not worried at all for not keeping a track of their service related records like leaves, recovery of different types of loans, tax calculations etc. The tax card of the employees as well as pay slip, IT card, PF statement, Loan statements (Housing/Car) are just one click way. In some of the employee service portal, even has a link provided to 'Objected Bills' of the employees. This has also saved a lot of time for the HR personnel, which was earlier spent on answering queries from the employees. These intranet sites are successfully linked with the SAP network, which is made record retrieving real time. It brings about a degree of transparency, which earlier was not possible with the manual record keeping system. Such employee service portals contribute positives in bringing higher employee engagement many organizations.

All employee information can be easily tracked and reported against. Custom fields of data can easily be added and configured. Dozens of canned reports are available across all areas of functionality and the search/query capability enables quick acquisition of data. Data areas include, but are not limited to personal information, work history, disciplinary items, skills, competencies, career planning, appraisals, performance, training, health and safety incidents, succession planning, and more. All of which can be administered and recorded through Employee Self Service (Antony \& Datta, 2007). Scroggin (2008) indicates that employee access is the main purpose of ESS systems. Employees have the ability to view or update their own information without having to communicate with HR or their managers to do so. This access may include simple demographic data, emergency contacts, attendance details, benefits, training, payroll information, or insurance plan details. When an ESS product is setup, an HRMS software administrator will typically have the option to define field by field what information employees can view, not view, or update. There may also be situations where they can change data but that change must be approved by others before the change is live. Brockbank \& Ulrich (2000) a recent study indicates that companies with the most high-performing HR function behave differently when it comes to the use of HR technology and this may be the most convincing reason for HR professionals to improve their knowledge and skills in this competency domain. A recent study from a global business process advisory firm, the Hackett Group, found that a significant cost gap exists 
between world-class and typical companies, with world-class companies now spending $25 \%$ less than their peers. The high-performing companies examined for this study, which were defined as companies ranking in the top $25 \%$ in efficiency and effectiveness metrics, also operated with $16 \%$ fewer HR staff. More efficient use of IT was considered a major factor behind the ability of these companies to operate with lower costs and fewer HR employees. Self-service technology appeared to play a role in these higher levels of efficiency and productivity. Employee Self-Service (ESS) - HRIS applications have obtained wide recognition over the last several years. Employees may be able to bring up to date their emergency contact information, and access to many facilities in organization like personal contact information, see their pay slip, Provident fund statement, Loan statements, Payroll and Pension information, Information Technology card, Career planning, Appraisals, Performance, Training, Health and Safety incidents, Benefits Open Enrollment, through portals. (Vishnu Bhadran, Mindlance India, lead-corporate RMG).

Technology and Workflow technologies (Business Process Management): Scroggin (2008) indicates that Work Flow Management - is very important capability under the employee access option section. With this option, one can designate an approval process for any changes that may occur in the system. For example, an employee requests time off, the manager then may approve or disapprove this time, if they approve it, the information may move to human resources to make a final approval. If the manager is out of the office, they will typically have the capability of designating a temporary approver while they are out.

Technology and Applicant Tracking Systems: Organizations are constantly facing a daily challenge of fierce competition for skilled resources whilst having to balance that with reductions in recruitment budgets and diminishing numbers of resources to administer the recruitment process. The Society for Human Resource Management has published a Workplace Trends during 2007-2008 indicates that:

- There is high demand for skilled workers, e-recruiting tools and the mobility of the workforce.

- Organizations are in high competition for a shrinking supply of workers.

- HR professionals are demanding increased customization of products and services from outsourcing partners.

- Greater prevalence of HR outsourcing and increased use of HR technology.

- An increase in Business Process Outsourcing (BPO) including recruiting.

- Continued increase in the use of technology in the practice of recruiting.

- Increasing use of assessments in the selection process.

- Continuing growth of application service provider/outsourcing versus in-house software implementations.

Gara (2008) states that Applicant Tracking Systems (ATS) are increasingly moving online, i.e. web-based ATS, making it easier for customers to sign up and get started. The basic purpose of an applicant tracking system is to aid an organization's administration, or more specifically the HR department, in keeping a track of their incoming job applications, and in turn helping them hire the right people. Web-based applicant tracking system that aids organizations in keeping their incoming job applications and resumes neatly organized in one place, therefore increasing their HR productivity and helping them hire the right people for their organization. Web-based applicant tracking system lets users sign up online and start using the system in minutes. It is most easy-to-use; cost-effective, it lets organizations streamline their hiring workflow, resulting in a better and more efficient hiring process. The system also tracks applicants' status as they move through this workflow, and allows users to retrieve all applicants at a certain stage, thus giving them control over their applicants at all times. It further makes it very easy to maintain an ever-growing database of resumes, including applicants who are not hired due to limited requirements. As the company grows, the system also allows the organization to dig up these candidates and make offers to them, hence giving the organization an always-available pool of potential human resources. If the company HRMS software offers a recruiting option, one may also be able to offer in house recruiting options to your employees. They may be able to view a job, the description and requirements or post directly for a job.

Industries are trying to fine tune with technology applications, especially in Human Resource functional level. The HRMs software applications support an organization to be effective in resume management. An organizations Applicant Tracking System (ATS) support the HR managers in data migration, by tying up with 
major recruitment portals. Applicant tracking system act as a central location and database for an organization's recruitment needs. Applicant Tracking System (ATS) permits HR Managers to be as professional and efficient in supporting the employer and improving the candidate experience. (Shilpa Wagh, Sr. HR Manager, iFelx Solutions). Sing (2006) in this context indicates that recruitment is one area where all the companies worth their name leverage IT. There are two different models of e-recruitment, which are in vogue. One is recruitment through company's own sites and the other is hosting your requirement on the other sites e.g., monster .com, jobsdb.com, jobsahead.com, naukri.com, and jobstreet.com and so on so forth. The first models is more popular with the larger companies who have a brand pull for potential employees e.g., G.E., IBM, Oracle, Microsoft, HCL, ICICI, Reliance, Mindtree consulting etc. Other companies prefer to go to the job sites. Some are adopting both. In the early days e-recruitment was plagued with flooding the employers with lowquality bio-data's. Again technology has come as a savior. Now pre-employment testing like the one introduced by Capital One, a US based financial company, help in filtering the applicants. These tools test online e.g., applicants for call centers. 'Profile International' a Texas based provider of employment assessments, has developed tools that allow instant translation of assessment tests between languages.

Further developments like video- conference specialized sites, online executives recruitments and combining online and offline methods are leading to more and more companies adopting e-recruitment at least as a secondary recruitment method. Arena Knights Bridge, a US based IT company conducts video-based interview of its prospective employees and only short listed employees are met in person. Even Cisco was to launch the same. Substantiating the role of technology HR Magazine (2008) further reports that because the growth of e-recruitment technologies has made applying for jobs simpler and more streamlined, applications are on the rise-from strong candidates and from those less qualified. Recruiters are relying increasingly on e-recruiting technology to help narrow the field, underscoring the importance of job, matching technology and of finding ways to use the Internet to better connect with the most qualified job seekers.... [Recruiter needs] drive the development of integrated technologies capable of culling multiple data sources and coming up with detailed supporting information on job candidates... Development is continuing on more focused, custom technologies for shrinking the range of applicants by job fit while expanding the detailed information about individual candidates. Such advances are likely to have a broader influence on recruitment procedures overall.

Technology and Performance management software: Vasundhra (2007) evaluating employee performance requires a systematic approach and a streamlined process. With the advent of technology, performance appraisal software's are becoming common in organizations. Performance management software is also helping to dramatically improve HR's ability to carry out effective people relationship management (PRM), and improve their organization's employer brand. It enables companies to move away from subjective people management to objective and efficient people management to the great benefit of the employee / candidate. The performance appraisal software's are used to:

- Integrate organizational goal and competency management

- Professional and career development strategy

- Employee evaluation form

- Automated performance management workflow

- E-mail reminders

- Report generation and compatibility with the HR system and software's

Mayasoman (2007) indicates that Infosys BPO migrated to the online performance management system called 'Performagic' in the January 2006 appraisal cycle. This is an online appraisal tool wherein the whole appraisal cycle is completed on the system itself. This tool has been developed by our parent organization "Infosys Technologies" and is used by the Infosys group of companies. The tool opens only twice a year for our employees during the appraisal cycles and is easily accessible to all employees as the link for the same is available on the company intranet. The system is used simultaneously used by more than 10,000 employees at a time to complete their appraisals. This unique system allows for employee evaluation not only on the tasks assigned to him/her but also the competencies that have been defined for the particular band level. While describing the advantages of the 'Performagic' the author further indicates that

- It's an online system for capturing the appraisal feedback of the employees. 
- It is a useful system to capture Appraisal information wherein the data can be captured at all the stages.

- It also helps the employees to view their past cycle forms along with the current one.

- It gives the option of the Consultant (Previous or Parallel Manager) who can give his/her inputs for a fair appraisal.

- Complete confidentiality of the form is maintained.

- The appraisal form can be traced at all stages.

- It is a transparent tool, which saves on time.

The underlying guiding principal of the entire performance management system is to build a high performance work ethic in the organization where there is no place for satisfactory under-performance. In a high performance work ethic organization, performance management serves as the backbone for most of the HR systems. The online performance management system ingrates these operational concepts viz., performance and ethics through transparent appraisal system (Mayasoman, 2007). "IT platforms free the HR professionals from being mere book-keepers of labor statistics. They provide them with an opportunity to play a key role in organizational renewal and revitalization....HRMS helps in generating critical reports on the demographics profile, performance on an individual basis, team performance etc., which help the business to do deep dive analysis, especially while planning and reallocation of resources. It also serves as a single repository for the business to access information on employees located in different locations, across the globe. (Venkatesan, (2001) Senior Vice-president, Global Human Resource, ISGN)

Technology and Pay Roll: Partho (2005) indicates that payroll model automates the pay process by gathering data on employee time and attendance, calculating various deductions and taxes, and generating periodic pay-cheques and employee tax reports. Data is generally fed from the human resources and time keeping modules to calculate automatic deposit and manual cheque writing capabilities. Sophisticated HCM (Compensation Management) systems can set up accounts payable transactions from employee deduction or produce garnishment cheques. HRMS Solutions INC (2007) point out that that the payroll module sends accounting information to the general ledger for posting subsequent to a pay cycle. Produce paychecks on demand, run trial reports, and make last-minute changes with no hassle. Flexible features include simplified pay processing, Comprehensive reporting, Check printing, Direct Deposit, Tax Management, Earning etc. Manage the flow of employee information and make changes to payroll quickly and easily with Sage HRMS Payroll, the cost-effective payroll management solution. Integrate your payroll data to leading financial accounting packages, deposit employee pay to an unlimited number of banks, reconcile payrolls and quarterends with up-to-the-minute facts and instant analysis, retain all of the payroll transactions for an unlimited time period without having your data purged by your payroll provider. "It is observed that delivering payroll information electronically is applied in many companies. The pay role application reduces the cost of distributing payroll information. The most significant feature of this IT application is that it is more accessible to employees. It ensures better service at employee level and the administrative simplicity for the managers." (Arun Sreedharan, SAP Functional Consultant Business Analyst, Wipro)

\section{Technology and HR and Business Excellence}

Organizations have begun to realize the importance of HRM in achieving a better competitive advantage (Greer 1995, Husleid, 1995 \& Hussain, 2002). Technology has been cited as a critical driver of HR's transition from a focus on administrative tasks to a focus on serving as a strategic business partner. This strategic role not only adds a valuable dimension to the HR function, but also changes the competencies that define the success of HR professionals. Emphasizing the importance of IT and HR effectiveness. Faiz (2001) report that the HR department of any organization cannot function without IT solutions to make its task easier and more efficient. Use of technology in HR management now goes beyond the context of just managing the payroll system and other databases. Organizations today see it as an effective tool for talent management and a means for increasing employee productivity and skills. The functions provided by HRIS that allow for the type and amount of the information provided to top management and the effectiveness of the HR department to make better decisions are important in research of the system (Lengnick-Hall and Moritz, 2003). A general purpose of an HRIS is to provide decision support applications that help HR and non-HR managers, as well as 
employees, make better decisions, and the key is to make better decisions rather than simply produce data faster (Kovach and Cathcart, 1999). Leslie (2005) states that advances in Web-based technology in particular and computer technology in general will continue to be a driving force behind advances in the knowledge economy. A critical success factor influencing an organization's ability to lead, simply languish or ultimately falter in the marketplace will eventually come to rest on the positive synergy the organization is capable of generating between the human capital assets in its employ and the judicious investments in technology that it makes in its efforts to remain abreast of the competition.

HRIS would reduce HR costs by automating information and reducing the need for large numbers of HR employees; by helping employees to control their own personal information; and by allowing managers to access relevant information and data, conduct analysis, make decisions, and communicate with others without consulting an HR professional (Awazu \& Desouza, 2003; Ball, 2001). Ideally, with an appropriate use of HRIS, less people should be needed to perform administrative tasks such as record keeping and more time would be made available for HR managers to assist by providing data on a strategic level. Many of these authors believe the future to be bright for HRIS as it creates new paths for human resources and for the organizations that effectively use HRIS. One study even goes as far as to suggest that there is evidence that HRIS can improve shareholder value (Brown, 2002). Snell et. al. (2002) suggests that e-HRM technology is capable of more than simply automating business processes, enabling organizations to become more strategic and flexible as well as cost-efficient, by supporting people management. Several other writers including Davenport (1993), Gourley and Connolly (1996), Hannon et al (1996), Liff (1997), Othman \& The (2003) and Tyson and Selbie (2004) have argued the potential of a shift away from administrative applications towards supporting people management processes. Kossek et al. (1994) have noted the role of an HR Information System in strategic positioning that can practically and symbolically represent the transformation of Human Resources into a strategic business partner. "HRIS as strategic partner is getting impetus as being one of the best way yet in making human resources as the most important asset for organizational effectiveness and sustainable business excellence. By making a strategic alliance "the organization is ensuring a long-term relationship to achieve defined objectives common to all partners." (Vishal Dalvi, HR Manager, L\&T)

There are several advantages to firms in using HRIS (Beckers \& Bsat, 2002). They include the following:

- Providing a comprehensive information picture as a single, comprehensive database; this enables organizations to provide structural connectivity across units and activities and increase the speed of information transactions (Lengnick-Hall \& Lengnick-Hall, 2006)

- Increasing competitiveness by improving HR operations and improving management processes

- Collecting appropriate data and converting them to information and knowledge for improved timeliness and quality of decision making

- Producing a greater number and variety of accurate and real-time HR-related reports

- Streamlining and enhancing the efficiency and effectiveness of HR administrative functions

- Shifting the focus of HR from the processing of transactions to strategic HRM

- Reengineering HR processes and functions

- Improving employee satisfaction by delivering HR services more quickly and accurately to them

\section{Technology Trends and Implications}

The technology application trends in Human Resource functional area have brought prime attention to many managerial implications to business operations and strategic decisions. Much such implication can be detailed as:

- Use of web for delivery and utilization of HR applications on a service basis

- HRIS application systems form the basic HR transactions to strategic applications

- Significant growth in the use of e-learning

- Expanded use of e-recruitment for talent acquisition

- Increased focus on measuring ROI for HR Technology systems

- Heightened awareness of HR Data Privacy

- Increasing outsourcing of HR Information Systems

- Better time and energy management 
- Effective talent management and performance management.

\section{Conclusion}

This particular research was conducted to understand the effect of technology, especially the Human Resource Information System (HRIS) on HR and Business Excellence. It is observed that implementing HRIS tools in HR and business operations support the HR department reduce administrative workloads and address higher-level issues. HRIS as a strategic tool that may be used to optimize workforce and human capital costs provide the organization with a glimpse of the skill gaps within the organization, help the organization to develop strategies that will bolster market value and make positive impact on the bottom line. While both specialized HR software and HRIS have its value, HRIS points the way to the future by not only improving process efficiencies but making HR a true business partner, allowing one to help drive the organization toward sustainable, long-term business success. Thus, Human Resource Information System can play an active role in strategic business excellence movements. Leveraging technology option thus has given decision makers quick access to role-relevant information, and an efficient platform to disseminate such information to its employees that further to improve greater efficiency, effectiveness, consistency, competency, organization flexibility, and customer - focus and profit responsibility at large. Leveraging high technology thus may lead to both Human Resource and Business Excellence across sectors and industries.

\section{Reference}

Antony, R. \& Datta, S. (2007). HRIS and Employees Services, Indian Oil Experience, Conference Proceedings, IHRD - HR Summit, Bangalore.

Awazu, Y. \& Desouza, K. C. (2003). Knowledge Management. HR Magazine, 48(11), 107.

Ball, K. S. (2001). The Use of Human Resource Information Systems: a Survey. Personnel Review, 30(6), 667693

Barber, A. E. (1998). Recruiting Employees: Individual and Organizational Perspective, Sage Publications, Thousand Oaks, and CA. 8.

Barron, M., Chhabra, D., Hanscome, R. \& Henson, R. (2004). Exclusive Panel Discussion: Tips and Trends in HRIS. HR Focus, 81, 6-7.

Beckers, A. M. \& Bsat, M. Z. (2002). A DSS classification model for research in human resource information systems. Information Systems Management, 19, 41-50.

Breaugh, J. A. (1992). Recruitment: Science and Practice, Boston: PWS-Kent.

Brockbank, W. \& Ulrich, D. (2000). Competencies of New HR. Arlington, V.A: Society of Human Resource Management.

Brown, D. (2002). EHR - Victim of Unrealistic Expectations. Canadian HR Reporter, 15(16), 1-6.

Bussler, L. \& Davis, E. (2002). Information systems: The quiet revolution in human resource management. Journal of Computer Information Systems, 42(2), 17-20.

Casper, R. (1985). Online Recruitment. Personnel Journal, 64(5), 4-5.

Cedar Enterprise Solutions, Inc. (2004). Cedar 2004 workforce technologies survey, 7th annual edition. Retrieved on Décembre 10, 2008. Citation : www.TheCedarGroup.com.

Chapman, D. \& Webster, J. (2003). The Use of Technologies in Recruiting, Screening, and Selection Processes for Candidates. International Journal of Selection and Assessment, 11(2/3), 113-20.

CIPD. (1999). The IPD Guide to using your computerized Personnel Effectively, IPD, London.

Cullen, B. J. (2001). Winning the War for Talent: E-recruiting Best Practices, Cambria Consulting, and Boston, MA.

Edelman, D. (2004). Engaging your Employees in New Technology Launches. Employee Thinking November 2004.

Faiz, A. (2001). Leveraging IT in HR. Indian Express Newspapers (Mumbai) Limited.

Gallagher, S. (1997). Human Resource Management Software, Conspectus, PMP (UK) Ltd.

Gara, S. J. (2001). How an HRIS can impact HR: a complete paradigm shift for the $21^{\text {st }}$ century. Society for Human Resource Management (SHRM) White Paper, Retrieved November 17, 2002, from http://www.shrm.org/ whitepapers /documents/default.asp? page=630 01.asp 
Gatewood, R. W., Gowan, M. \& Lautenschlager, G. (1993). Corporate Image, Recruitment Image and Initial Job Choice Decision. Academy of Management Journal, 36(2), 414-22. 34.

Gentner, C. (1984). The Computerized Job Seeker. Personnel Administrator, 29(8).

Gourley, S. \& Connolly, P. (1996). HRM and computerized information systems - have we missed a link? Paper presented at conference - strategic direction of HRM

Greer, C. (1995). Strategy and human resources: A general managerial perspective. Englewood Cliffs, NJ: Prentice Hall.

Grossman, R. J. (2000). Measuring Up: Appropriate Metrics Help HR Prove its Worth. HR Magazine, 45(1), 2835. 38,

Gueutal, H. G. \& Stone, D. L. (2005). The Brave New World of eHR: Human Resources Management in the Digital Age, Jossey-Bass, San Francisco, CA. 40].

Hannon, J., Jelf, G. \& Brandes, D. (1996). Human resource information systems: operational issues and strategic considerations in a global environment. International Journal of Human Resource Management, 7(1), 245-269.

Hoffman, I. (2001). Knowledge management tools. In K. Mertins, P. Heisig, \& J. Vorbeck (Eds.), Knowledge management: Best practices in Europe, 74-96.

Hogler, R. L., Henle, C. \& Bemus, C. (1998). Internet recruiting and employment discrimination: a legal perspective. Human Resource Management Review, 8(2), 149-164

HR Magazine. (2008). HR Screening Technology Trends and Fast Facts, Cited in Need for New Screening Technology, Harquen Voice Screener, Online document.

HR Portal. (2003). Introduction to Online recruitment, http://www.hrmguide.co.uk/recruitment/ introduction_to_online_recruitment.htm Accessed date: 5 April 2003.

HRMS Solutions INC. (2007). Sage Abra Payroll - In-house Payroll Software, NW Washington. Retieved from URL: www.hrmssolutions.com.

Human Capital Management. (2009). Global PeopleSoft HRMS upgrade, Infosys Technologies Limited. Online Publication.

Huselid, M. A. (1995). The Impact of Human Resource Management Practices on Turnover, Productivity, and Corporate Financial Performance. Academy of Management Journal, 38(3), 635-672.

Hussain, Z. I. (2002). An investigation into the Strategic Use of Personnel Management Information Systems (PMIS) by Human Resource (HR) Managers, Master's Thesis, Sheffield Hallam University, UK.

Hussain, Z., Wallace, J. \& Cornelius, N. E. (2007). The Use and Impact of Human Resource Information System on Human Resource Management Professionals. Information and Management, 44(1), 74-89.

Karthik, F. (2007). HR Practice in 24/7. Citation: Paper Presented in Bangalore HR Summit 2007 on Dec. 7 \& 8, (2007) at Le Meridien, Sankey Road, Bangalore-52. India.

Kossek, E. E., Young, W., Gash, D. C. \& Nichol, V. (1994). Waiting for innovation in the human resources department: Godot implements a human resources information system. Hum. Resource. Manage., 33, 135-159.

Kovach, K. A. \& Cathcart, J. \& Charles, E. (1999). Human Resource Information Systems (HRIS): Providing Business with Rapid Data Access, Information Exchange and Strategic Advantage. Public Personnel Management, 28(2), 275-282.

Lengnick-Hall, C. A. \& Lengnick-Hall, M. L. (2006). HR, ERP, and knowledge for competitive advantage. Human Resource Management, 45(2), 179-194.

Lengnick-Hall, M. L. \& Moritz, S. (2003). The Impact of E-Hr on the Human Resource Management Function. Journal of Labor Research, 24(3), 365-79.

Lepak, D. P. \& Snell, S. A. (1998). Strategic Human Resource Management in the $21^{\text {st }}$ Century. Human Resource Management Review, 8(3), 215-34.

Leslie, A. W. (2005). HR Technology: Leveraging the Shift to Self-Service-It's Time to Go Strategic, HR Magazine, March 2005, downloaded from Infotrac at http://web7.infotrac.galegroup.com

Liff, S. (1997). Two routes to managing diversity: individual differences or social group characteristics. Employee Relations, 19 (1), 11-25.

Lilly, F. (2002). Web-based training: Moving from c-learning to e-learning [SHRM White Paper]. Retrieved December 8, 2004, from www.shrm.org/hr resources/whitepapers published/CMS_000217asp. P-40.

Mayasoman, T. (2007). Performance management, Citation: Paper Presented in Bangalore HR Summit 2007 on Dec. 7 \& 8, (2007) at Le Meridien, Sankey Road, Bangalore-52. India. 
Mercer Human Resource Consulting. (2004). Transforming HR for business results: A study of US organizations. Retrieved December 18, 2004, Retreived from www.mercerhr.com/referencecontent.jhtml?idContent=1119865.

Mottl, J. (1998). Want to find workers? Go online many IT job seekers flock to the Web; managers may soon follow. Internet week. 728, 20-21.

Nakache, P. (1997). Cisco's Recruiting Edge. Fortune, 136(6), 275-6.

Ngai, E. W. T. \& Wat, F. K. T. (2006). Human Resource Information Systems: A Review and Empirical Analysis. Personnel Review, 35(3), 297-314.

Othman. R. \& The, C. R. \& The, C. (2003). On developing the informated work force: HRM issues in Malaysia. Human Resource Management Review, 13(3), 393-406.

Overman, S. (1992), Reaching for the $21^{\text {st }}$ Century. HR Magazine, 37, 61-63.

Partho, P. C. (2005). A Realistic of Human Resource Management Systems (HRMS), 1-3. Citation: Faculty article, www.indianmba.com. (Retrieved on February 2007).

PeopleSoft, Inc. (2003). Heads count: An anthology for the competitive enterprise. Pleasanton, CA: PeopleSoft, Inc.

Pomeroy, A. (2000). Ema Keynote Speaker Says Recruiters Must Declare War. HR News, 19(6), 1-16.

Rekhi, S. (2001). Human Resource Information System. Citation: Paper Presented in Bangalore HR Summit 2007 on Dec. 7 \& 8, (2007) at Le Meridien, Sankey Road, Bangalore-52. India.

Rynes, S. L. (1991). Recruitment, Job Choice, And Post-Hire Consequences: A Call For New Research Directions, in Dunnette, M.D. and Hough, L.M. (Eds), Handbook of Industrial Organizational Psychology, 90, 399-444.

Sara, G. (2008). Applicant Tracking System, Article Alley. Retrieved from http: // www.articlealley.com / article_589557_36. Html (Retrieved on February 2007).

Schreyer, R. \& McCarter, J. (1998). The Employers Guide to Recruiting on the Internet Impact: Virginia: Impact Publications Manassas Park.

Scroggin, C. (2008). HRMS Software - Employee Self Service (ESS) Defined. HRMS Software - Employee Self Service (ESS) Defined EzineArticles.com. Retrieved from URL: http://ezinearticles.com/?HRMSSoftware---Employee-Self-Service-(ESS)-Defined \& id=1643062 (Retrieved on March 2009).

Sing, S. (2006). IT for Organizational Excellence, faculty article, www.indianmba.com. 1-2. (Retrieved on March 2008).

Snell, S. A., Stuebner, D. \& Lepak, D. P. (2002). Virtual HR departments: Getting out of the middle. IN R.L.Henneman, D. B. G. (Ed.) Human Resource Management in virtual organizations. Greenwich, Information Age Publishing.

Tannenbaum, A. (1990). HRIS: user group implications. Journal of Systems Management, 41(1), 27-32.

Temple, P. (2000). Technology on the fly. Workforce (May issue), 10.

Thomas, A. \& Datta, G. (2007). Technology in Employee Communication: Indian Oil perspective.

Turban, D. B. \& Greening, D. W. (1997). Corporate Social Performance and Organizational Attractiveness to Prospective Employees. Academy of Management Journal, 40(3), 658-72. 100].

Tyson, S. \& Selbie, D. (2004). People processing systems and human resource strategy. International Journal of HR Development and Management, 4(2), 117-127.

Ulrich, D. (1997). Human resource champions: the next agenda for adding value and delivering results Boston: Harvard Business School Press.

Vasundhra, S. (2008). Performance Appraisal System: Citation: Paper Presented in Bangalore HR Summit 2007 on Dec. 7 \& 8, (2007) at Le Meridien, Sankey Road, Bangalore-52. India.

Venkatesan, H. (2001). Leveraging IT in HR, Indian Express Newspapers (Mumbai) Limited. Report, Retrieved on December 15th, 2008.

Walker, A. J. (1982). HRIS Development, Van Nostrand Reinhold, New York. 